\title{
Intuitionistic Fuzzy Weighted Sum and Product Method for Electronic Service Quality Selection Problem
}

\author{
Gaurisha Sisodia \\ Department of Computer Science \& Engineering, ITM Gwalior University, Gwalior-474005, MP, India \\ Email: aditi.as385@gmail.com \\ Kapil Sharma \\ Department of Computer Science \& Engineering, ITM Gwalior University, Gwalior-474005, MP, India \\ Email: Kapil.sharma.cse@gmail.com \\ Shashikant Gupta \\ Department of Computer Science \& Engineering, ITM Gwalior University, Gwalior-474005, MP, India \\ Email: shashikantgupta@itmuniversity.ac.in
}

Received: 19 July 2018; Accepted: 07 August 2018; Published: 08 September 2018

\begin{abstract}
The increasing growth of internet and ecommerce had bartered the customer's purchasing feature and service providers' service policies. Moreover, there is no other criterion for quality of service (QoS) on the online network. Here the paper's objective is to employ the importance of QoS to measure the utility quality of monetary enterprise on internet (e.g., Facebook (FB)). In this paper, the Weighted Sum method and Weighted Product method (WSM and WPM) are implemented using FB for their promotion and advertisement and then utilized the intuitionistic fuzzy value for the measuring of the QoS. The proposed methods are generally based on IF-aggregation operators and criterion weights. To calculate criterion weight, new intuitionistic fuzzy divergence is developed. Additionally, the IF-TOPSIS (technique for order preference by similarity to ideal) algorithm is also applied to check the validity of the result. This research examine not only the dimensions of QoS that users on FB liked and major brands are 'preferred by' by them, and which results as the most highly ranked features.
\end{abstract}

Index Terms-Entropy measure, Divergence measure, WSM, WPM, TOPSIS, Electronic service quality.

\section{INTRODUCTION}

In early times decision making has been done with the traditional methods. With the surging increase in users of online network decision making behavior has been changed, and sharing information with the social media, provides a better reference for decision making by(Court, Elzinga, Mulder, \& Vetvik, 2009)[13].Communicating sites (e.g., Facebook (FB), Twitter, Plurk, YouTube) and other types of online network services in modernistic years have grown dominating throughout the globe, and count of entities or businesses have emerged into communicative practices (Edelman,2010)[12]. Additionally it motivates for providing service excellency in products, outlook market tendency, and highly increases the efficiency of their advertisement on social media (Constantinides, Romero, \& Boria, 2008)[16]. This also emphasizes business communications with users, to uprise communications with company websites, and search more service contingency(Michaelidou, Siamagka, \& Christodoulides, 2011)[29].(Rust, 2001)[36] proposed the approach as "the foundation of service over electronic networks". His determination was at the combination of the major establishment in the world of business. The increasing development of service ability and the rising compliance of informatory and communicating technology like a interchanging pathways, through online networks. There is abundant indications that quality of service conveyance had a conclusive blow on passionate opinion, discoverable, and commercial assistance(Cronin Brady, and Hult 2000)[25]. Additionally, this approach in which quality of service (QoS) opositively effects internet services achievement have been deep rooted (Yang \& Fang, 2004; Zeithaml, Parasuraman, \& Malhotra, 2002)[46,43] . Moreover, the article emphasizes on the communication which is established among quality of service and value perceived, and the encounter them according to user fulfillment, corporate apperance, and acceptations (Al Dmour, Alshurideh, \& Shishan, 2014; Wu, 2014; Hu, Kandampully, \& Juwaheer, 2009; Cronin, Brady, \& Hult, 2000) [6,45,21,25].

Scholarly analysis on electronic commerce involves consideration of subjects such as how e-WOM influences the reaction of users (Zhang et al., 2010)[23], this consequence with internet survey parameter (Lee \& 
Shin, 2014)[15], goals of Facebook users (Dong, Cheng, \& $\mathrm{Wu}, 2014 ; \mathrm{Ku}$, Chen, \& Zhang, 2013)[41,48], promoting on communicative websites (Saxena \& Khanna, 2013) [1], dynamism on facebook practice (Kuo \& Tang, 2014) [42] , quality assessment on communicative sites (Naylor, Lamberton, \& West,2012) [35], and the Web plays a correlation among e-services and customers (Michaelidou et al.,2011) [29].The presently used service quality models do not consistently cover activities of customers on internet. The introduction of social media operation has transform the way of management of business institutions their relationship with customers or also known a Customer Relationship Management (CRM). Traditional CRM or CRM 1.0 is used more to manage consumer's information make profitable decisions (Mohan, Choi, \& Min, 2008; Greenberg, 2010)[38,31].

These developing circumstances has gained attention to research for examining SNS users' behavior, originating profitable research results in fields such as advertisement, orientation management, and artistic studies. In particular, considering a user's interest is important for explaining the user's various activities while engaging in online associations. One intermittently approved approach to examine those motivational attributes of SNS users are based on uses and gratifications (U\&G) concept. Another, research is needed to explore the interconnecting aspects of SNS users' online experience of the interrelation between social gratifications.

\section{LITERATURE SURVEY}

Particularly, social media merges electronic-service sites with Web 2.0 to represent a stage for e-commerce (Constantinides et al., 2008)[16]. Now how service quality of social commerce to be calculated has become an emerging issue. Prior to the introduction of ecommerce, an advanced approach- The network service had emerged as a brand-new business application. Additionally, internet quality of service had a heavy punch on most of the aspects of electronic business that is the reason for a trend of researchers to enforce and aggregate their research in this upcoming area of interests. The ancient evolution of the internet quality of service of literature represents numerous theoretical concepts and measuring techniques. There can be two methods to develop dimensions of quality of service of internet. The dimension attempted to determine QoS as the layout as well as properties of service providers which added attributes that leads to customer's fulfillment through a service provider (Alpar, Porembski, \& Pickerodt, 2001; Szymanski \& Hise, 2000)[34,11]. Alpar et al. (2001)[34] symbolized four factors of fulfillment using a service provider's functional benefit, knowledge of content, happiness, and accomplice. Liu and Arnett (2000)[10] additively marked the basic element of service providers qualification, those are, knowledge and quality of service, efficiency, privacy and design quality of the system, while Szymanski and Hise (2000)[11] defined various dominating attributes in customers' e-fulfillment, namely accessibility, advertising, site architecture, and economic compliance. And the next factor is, the analysts make efforts to advance more explicit and extensive attributes to construct the e-SQ.

The Weighted Sum method and weighted Product method is a decision making method was defined and anticipated by Zavadskas et al (2012), which has been practiced and continued in many resolutions making problems and circumstances. (Chakraborty and Zavadsk , 2014)[39] explored the method as an efficient MCDM tool while evaluating eight executing decision making problems. These advancements are the assimilation of Weighted Product Model (WPM) and Weighted Sum Model (WSM). (Zavadskas, Turskis, Antucheviciene and Zakarevicius, 2011)[24]represented this approach and contended that; the certainity of this approach strengthens the WPM and WSM. (Zavadskas, Turskis, Antucheviciene and Zakarevicius,2014)[18] suggested such new approach and demonstrated that this accumulated method executes more accurately than other methods . Recently, numerous studies organised using this approach to find a under-water port; (Zavadskas, Antucheviciene, Šaparauskas and Turskis,2011)[24] switched this to calculate the facade alternatives; (Bitarafan, Zolfani, Arefi, Zavadskas and Mahmoudzadeh,2013)[28]used the method to operate of real-time intelligent sensors for architectural monitoring of bridges; (Dejus and Antuchevičienè,2013)[14] applied it to estimate health and safety results on the construction site; and (Hashemkhani Zolfani, Aghdaie, Derakhti, Zavadskas and Morshed Varzandeh,2013)[40] used WSM and WPM for decision making by considering business issues in the insight perspective.

In the decision making process, the criterion weight determination is a vital issue for the accuracy of evaluation results, for this reason, various weightdetermining methods have been launched by many authors. At a time, FSs and its extensions have gained more attentiveness in the field of decision making because of increasing intricacy and limitation of time, so that, copious MCDM methods such as COPRAS (Mishra et al. 2018a)[8], TOPSIS (Mishra et al. 2018a[8], TODIM (Mishra and Rani, 2018; Rani et al. 2018a)[8,37], VIKOR (Mishra and Rani, 2017; Rani et al. 2018b)[4,33] PROMETHEE (Rani and Jain 2017)[32], WASPAS (Zavadskas et al., 2012; Mishra et al, 2018b)[19,9] and many others have been generalized under uncertain decision atmosphere with diverse weight-determination approaches. Vijay athawale (et.al.2010)[44] preferred the most applicable CNC machine is by using TOPSIS (technique for order preference by similarity to ideal) algorithm, which has been an effective MCDM (multi criteria decision matrix) method for solving various types of complicated decision-making problems in construction domain. It was conceded that application of TOPSIS algorithm to be adequate and computable to evaluate and select the appropriate machine tool from a provided set of attributes. Abhang et al (2012)[27] suggested best lubricant in inclining process among numerous 
alternative lubricants in machining process of EN 31 steel work piece by using incorporate MADM. They have implemented TOPSIS model and concluded that the lubricant index assesses and ranks best lubricant at the time when steel turning operation and contribute an suitable method for solving complex MADM problems in construction domain. Nikunj et al (2012)[29] represented logical advancement for tool Insert Selection for Inclining Operation on CNC Turning Centre positioned on three well known Multiple Attribute Decision Making (MADM) approach such as TOPSIS. Mishra (2016)[2] and Mishra et al (2017)[5] proposed fuzzy TOPSIS and IF-TOPSIS method based on the similarity measure and intuitionistic fuzzy entropy for MCDM problem to rank the alternatives.This advancement is an assimilation of Weighted Product Model (WPM) and Weighted Sum Model (WSM) and TOPSIS (Technique for Order Preference by Similarity to Ideal System) algorithm that rank the rising development of services and the growing compliance of information and communication technology as a transposing medium,through Internet using facebook acoounts of top ranking social commerce companies, the criterion weight is evaluated by proposed divergence measure for IFSs. This will help in outranking the top performer with providing highest rank. Therefore, it may help consumers to consider only the ranked service providers in MP work. Additionally, it may help the consumers to chose the best service providers and also to the top brand companies improve the services by benchmarking the top rankers.

\section{PRELIMINARIES}

In this section, some fundamental ideas about FSs, divergence measure for FSs \& IFSs are discussed. In fuzzy sets, the association of an component is stated for value from the interval $[0,1]$ and the non membership is simply its complement. But, actually, these assumptions do not satisfy with human perception. Thus, Atanassov (1986)[26] extended the concept of fuzzy sets (FSs) to intuitionistic fuzzy sets (IFSs) by characterizing membership function and a non membership function such that the sum of both values is less than or equal to one [Mishra (2016)[2], Ansari et al (2018)[7]].

Definition 1. (Atanassov (1986)[26]). An IFS $Z$ on discourse set $P=\left\{p_{1}, p_{2}, \ldots, p_{n}\right\}$ is given by

$$
Z=\left\{\left\langle p_{i}, \alpha_{z}\left(p_{i}\right), \beta_{z}\left(p_{i}\right)\right\rangle: p_{i} \in P\right\}
$$

where $\alpha_{z}: P \rightarrow[0,1]$ and $\beta_{z}: P \rightarrow[0,1]$ are the degrees of membership and non- membership of $p_{i}$ to $\mathrm{Z}$ in $\mathrm{P}$ respectively, such that

$$
\begin{gathered}
0 \leq \alpha_{z}\left(p_{i}\right) \leq 1,0 \leq \beta_{z}\left(p_{i}\right) \leq 1 \\
0 \leq \alpha_{z}\left(p_{i}\right)+\beta_{z}\left(p_{i}\right) \leq 1, \forall p_{i} \in P .
\end{gathered}
$$

For an IFS $Z$ in $P$, we call the intuitionistic index (hesitancy degree) of an element $p_{i} \in P$ to $\mathrm{Z}$ the following expression:

$$
\begin{gathered}
\pi_{z}\left(p_{i}\right)=1-\alpha_{z}\left(p_{i}\right)-\beta_{z}\left(p_{i}\right) \\
0 \leq \pi_{z}\left(p_{i}\right) \leq 1, \quad \forall p_{i} \in P .
\end{gathered}
$$

For ease, the intuitionistic fuzzy number (IFN) is denoted by $\phi_{k}=\left(\alpha_{\phi_{k}}, \beta_{\phi_{k}}\right)$ which satisfies $\alpha_{\phi_{k}}, \beta_{\phi_{k}} \in[0,1]$ and $0 \leq \alpha_{\xi}+\beta_{\xi} \leq 1$. [Xu (2007)]

Definition 2. Let $\phi_{k}=\left(\alpha_{k}, \beta_{k}\right), \quad k=1(1) n$, be intuitionistic fuzzy values. Then

$$
\mathbb{S}\left(\phi_{k}\right)=\left(\alpha_{k}-\beta_{k}\right), \lambda(Z)=\left(\alpha_{k}+\beta_{k}\right),
$$

are, respectively, called the score and accuracy functions of the IFN $\phi_{k}$, where $\mathbb{S}\left(\phi_{k}\right) \in[-1,1]$ and $\lambda\left(\phi_{k}\right) \in[0,1]$ can be considered as net membership and accuracy degree, respectively.

Since $\mathbb{S}\left(\phi_{k}\right) \in[-1,1]$, when many score functions are aggregated with linear weighted summation method, it maybe appears that positive score functions are offset by negative score functions. Here, we define a new score function of IFNs as follows:

Defintion 3: Let $\phi_{k}=\left(\alpha_{k}, \beta_{k}\right), \quad k=1(1) m$, be intuitionistic fuzzy values.

Then

$$
\mathbb{S}^{*}\left(\phi_{k}\right)=\frac{1}{2}\left(\mathbb{S}\left(\phi_{k}\right)+1\right)
$$

are called a normalized score and uncertainty functions, where $\mathbb{S}\left(\phi_{k}\right)$ is given in (4). Obviously, $\mathbb{S}^{*}\left(\phi_{k}\right) \in[0,1]$.

Definition 4 (Xu (2007)): Let $\phi_{k}=\left(\mu_{k}, v_{k}\right)$, $k=1(1) n$, be intuitionistic fuzzy values, then IFWA operator is defined as follows:

$$
I F W A_{w}\left(\phi_{1}, \phi_{2}, \ldots, \phi_{n}\right)=\left[1-\prod_{k=1}^{n}\left(1-\alpha_{k}\right)^{w_{j}}, \prod_{k=1}^{n} \beta_{k}{ }^{w_{k}}\right] .
$$

Similarly, intuitionistic fuzzy weighted geometric (IFWG) operator is given as follows:

$$
I F W G_{w}\left(\phi_{1}, \phi_{2}, \ldots, \phi_{n}\right)=\left[\prod_{k=1}^{n} \alpha_{k}^{w_{k}}, 1-\prod_{k=1}^{n}\left(1-\beta_{k}\right)^{w_{k}}\right],
$$

where $w=\left(w_{1}, w_{2}, \ldots, w_{n}\right)^{L}$ is a weight vector of $\phi_{k}, k=1(1) n, \quad$ with $\quad \sum_{k=1}^{n} w_{k}=1, \quad w_{k} \in[0,1]$. 
Divergence measure is concerned to measure the discrimination information. Firstly, Vlachos \& Sergiadis (2007) introduced the divergence measure for IFSs. Afterwards, Montes et al (2015) introduced new axiomatic definition of divergence measure for IFSs.

Definition 5. (Montes et al. (2015)[22] ): Let $Y, Z \in I F S s$, then $M: \operatorname{IFS}(Z) \times \operatorname{IFS}(Z) \rightarrow \mathbb{R}$ is called a divergence measure or cross entropy, if it fulfills the following axioms:

(D1). $M(Y, Z)=M(Z, Y)$;

(D2). $M(Y, Z)=0$ if and only if $Y=Z$;

(D3). $\quad M(Y \cap Z Z \cap Q) \leq M(Y, Z)$ for every $Q \in \operatorname{IFSs}(Z)$;

(D4). $\quad M(Y \cup Q, Z \cup Q) \leq M(Y, Z)$ for every $Q \in \operatorname{IFSs}(Z)$.

Definition 6 (Szmidt and Kacprzyk (2001)[20]. A real valued function $h: \operatorname{IFS}(Z) \rightarrow[0,1]$ is called an entropy measure for IFSs if it satisfies the following axioms:

(P1). $h(Z)=0$ (minimum), iff $\mathrm{Z}$ is a crisp set;
(P2). $h(Z)=1$ (maximum), iff $\alpha_{Z}\left(y_{i}\right)=\beta_{Z}\left(y_{i}\right)$ for any $y_{i} \in Y$;

(P3). $h(Y) \leq h(Z)$ and if $Y$ is less fuzzy than $Z$, i. $e$.

$\mu_{Y}\left(y_{i}\right) \leq \mu_{Z}\left(y_{i}\right) \quad$ and $\quad \beta_{Y}\left(y_{i}\right) \geq \beta_{Z}\left(y_{i}\right) \quad$ for $\alpha_{Y}\left(y_{i}\right) \leq \beta_{Z}\left(y_{i}\right)$ or $\alpha_{Y}\left(y_{i}\right) \geq \alpha_{Z}\left(y_{i}\right)$ and $\beta_{Y}\left(y_{i}\right) \leq \beta_{Z}\left(y_{i}\right)$ for $\mu_{Y}\left(x_{i}\right) \geq v_{Z}\left(x_{i}\right)$ any $y_{i} \in Y$;

(P4). $h(Y)=h\left(Y^{c}\right)$.

Firstly, entropy measure for IFSs is proposed by Szmidt and Kacprzyk (2001)[20]. Here, we recall entropy measure for IFSs introduced by Mishra (2016)[2] to evaluate criteion weight of MCDM as follows:

$$
h(Y)=\frac{1}{2 n} \sum_{i=1}^{n}\left[\begin{array}{c}
\sin \left(\frac{\alpha_{Y}\left(y_{i}\right)+1-\beta_{Y}\left(y_{i}\right)}{2}\right) \pi \\
+\sin \left(\frac{\beta_{Y}\left(y_{i}\right)+1-\alpha_{Y}\left(y_{i}\right)}{2}\right) \pi
\end{array}\right]
$$

Based on Mishra et al (2016, 2017)[2,5], we propose new Jensen-Shannon divergence measure for IFSs as follows:

$$
\begin{aligned}
& h(Y, Z)=h\left(\frac{Y+Z}{2}\right)-\frac{h(Y)+h(Z)}{2} \\
& =\frac{2}{n} \sum_{i=1}^{n}\left[\ln \left\{\begin{array}{l}
\left(\frac{\alpha_{Y}\left(p_{i}\right)+\alpha_{Z}\left(p_{i}\right)+2-\beta_{Y}\left(p_{i}\right)-\beta_{Z}\left(p_{i}\right)}{4}\right) \exp \left(\frac{\beta_{Y}\left(p_{i}\right)+\beta_{Z}\left(p_{i}\right)+2-\alpha_{Y}\left(p_{i}\right)-\alpha_{Z}\left(p_{i}\right)}{4}\right) \\
+\left(\frac{\beta_{Y}\left(p_{i}\right)+\beta_{Z}\left(p_{i}\right)+2-\alpha_{Y}\left(p_{i}\right)-\alpha_{Z}\left(p_{i}\right)}{4}\right) \exp \left(\frac{\alpha_{Y}\left(p_{i}\right)+\beta_{Z}\left(p_{i}\right)+2-\beta_{Y}\left(p_{i}\right)-\beta_{Z}\left(p_{i}\right)}{4}\right)
\end{array}\right\}\right. \\
& -\frac{1}{2}\left\{\begin{array}{c}
\ln \left\{\begin{array}{c}
\left(\frac{\alpha_{Y}\left(p_{i}\right)+1-\beta_{Y}\left(p_{i}\right)}{2}\right) \exp \left(\frac{\beta_{Y}\left(p_{i}\right)+1-\alpha_{Y}\left(p_{i}\right)}{2}\right) \\
+\left(\frac{\beta_{Y}\left(p_{i}\right)+1-\alpha_{Y}\left(p_{i}\right)}{2}\right) \exp \left(\frac{\alpha_{Y}\left(p_{i}\right)+1-\beta_{Y}\left(p_{i}\right)}{2}\right)
\end{array}\right\} \\
+\ln \left\{\begin{array}{l}
\left(\frac{\alpha_{Z}\left(p_{i}\right)+1-\beta_{Z}\left(p_{i}\right)}{2}\right) \exp \left(\frac{\beta_{Z}\left(p_{i}\right)+1-\alpha_{Z}\left(p_{i}\right)}{2}\right) \\
+\left(\frac{\beta_{Z}\left(p_{i}\right)+1-\alpha_{Z}\left(p_{i}\right)}{2}\right) \exp \left(\frac{\alpha_{Z}\left(p_{i}\right)+1-\beta_{Z}\left(p_{i}\right)}{2}\right)
\end{array}\right\}
\end{array}\right\} .
\end{aligned}
$$

\section{WSM, WPM and TOPSIS method for IFSs}

Step 1: Consider set of alternatives and set of criteria In decision making process, our main goal is to choose the most appropriate variable from set of $m$ alternatives $S=\left\{S_{1}, S_{2}, \ldots, S_{m}\right\}$ with respect to the criterion set $P=\left\{P_{1}, P_{2}, \ldots, P_{n}\right\}$. Assume that a committee (group) of $t$ decision experts $E=\left\{E_{1}, E_{2}, \ldots, E_{t}\right\}$ has been constituted to determine the most suitable alternative(s).

Step 2: Construct performance evaluation linguistic table Compute decision experts' weights
Step 3: Construct performance evaluation table for alternatives and calculate aggregation table $\mathbb{Z}=\left[z_{i j}\right]_{m \times n}$ for smart phone selection problem

Step 4: Compute criterion weights for top brands selection problem

From eq. (8), compute the information of each intuitionistic fuzzy value in the intuitionistic fuzzy judgment matrix and get the information matrix of this judgment matrix as $D=\left(h_{i j}\right)_{n \times m}$, where $h_{i j}=h_{1}\left(\tilde{r}_{i j}\right)$.

Normalize the information values in the above decision matrix by using the equation 


$$
\bar{h}_{i k}=\frac{h_{i j}}{\max h_{i j}}, h=1,2, \ldots, m ; i=1,2, \ldots, n .
$$

And the normalized information matrix is expressed as $\bar{C}=\left(\bar{h}_{i k}\right)_{n \times m}$.

Step 5: Determination of weights of criteria

Compute the weight vector $\omega=\left(\omega_{1}, \omega_{2}, \ldots, \omega_{n}\right)^{T}$, where $\omega_{i} \geq 0$ and $\sum_{i=1}^{n} \omega_{i}=1$, by applying the given formula

$$
w_{j}=\frac{1-\sum_{j=1}^{m} \bar{h}_{i j}}{n-\sum_{i=1}^{m} \sum_{j=1}^{n} \bar{h}_{i j}}, j=1,2, \ldots, n .
$$

Step 6: Find out the positive-ideal and negative-ideal solution

In this method, the decision criteria can be classified into two criterias, benefits and cost. Let $C$ be a collection of benefit criteria and $F$ be a collection of cost criteria. As per intuitionistic fuzzy theory and principle of the classical TOPSIS method, positive-ideal $E^{+}$and negative-ideal solution $E^{-}$can be defined as follows:

$$
\begin{gathered}
E^{+}=\left\{\left(G_{j},\left\langle\max _{i} \mu_{i j}\left|j \in \mathrm{B}, \min _{i} \mu_{i j}\right| j \in F\right\rangle,\right.\right. \\
\left.\left.\left\langle\min _{i} v_{i j} j \in \mathrm{B}, \max _{i} v_{i j} j \in F\right\rangle\right): i=1,2, \ldots, n\right\}, \\
E^{-}=\left\{\left(G_{j},\left\langle\min _{i} \mu_{i j}\left|j \in \mathrm{B}, \max _{i} \mu_{i j}\right| j \in F\right\rangle,\right.\right. \\
\left.\left.\left\langle\max _{i} v_{i j} j \in \mathrm{B}, \min _{i} v_{i j} j \in F\right\rangle\right): i=1,2, \ldots, n\right\},
\end{gathered}
$$

where for each $j=1,2, \ldots, n$.

\section{IF-TOPSIS method}

Step 7: Calculation of divergence measures from positive-ideal and negative ideal solution

Using eq. (9), calculate the weighted divergence measure $M\left(E_{i}, E^{+}\right)$among the options
$E_{i}(i=1,2, \ldots, m)$ and the positive-ideal solution $E^{+}$ and the divergence measure $M\left(E_{i}, E^{-}\right)$among the options $E_{i}(i=1,2, \ldots, m)$ and the positive-ideal solution $\boldsymbol{E}^{-}$.

Step 8: Calculation of relative closeness coefficient (CC)

At last, relative closeness coefficient of each alternative with respect to intuitionistic fuzzy ideal solutions can be computed by using the following expression:

$$
\mathbb{S}\left(E_{i}\right)=\frac{M\left(E_{i}, E^{-}\right)}{M\left(E_{i}, E^{+}\right)+M\left(E_{i}, E^{-}\right)}, i=1(1) m .
$$

Step 9: Choose the highest value, denoted by $M\left(E_{k}\right)$, among the values $M\left(E_{i}\right), i=1(1) m$. And hence $E_{k}$ is the optimal choice.

Step 10: End.

\section{IF-WSM and IF-WPM Methods}

Steps 1-6: As the previous method.

Step 7: Compute weighted additive and product measures

Based on WSM [Triantaphyllou and Mann (1989)][17], total relative importance of $\mathrm{i}^{\text {th }}$ alternative as weighted sum (or additive aggregation measure) is estimated as

$$
S_{i}=\bigoplus_{j=1}^{n} w_{j} n_{i j}, i=1(1) m
$$

where $w_{j}$ is the jth criterion weight, $\sum_{j} w_{j}=1$.

Similarly, based on WPM [Triantaphyllou and Mann (1989)][17], the total relative importance of $i^{\text {th }}$ alternative (multiplicative aggregation measure) is calculated by

$$
P_{i}=\bigotimes_{j=1}^{n}\left(n_{i j}\right)^{w_{j}}, i=1(1) m
$$

Step 8: Calculate score values of $S_{i}$ and $P_{i}$ by using eq. (5).

Step 9: Rank the alternatives.

Step 10: End. 
Table I. Dimensions and Sub Dimensions as Criterias

\begin{tabular}{|c|c|}
\hline Dimension (abbreviation) & Subdimensions (abbreviation) \\
\hline 1.Reliability (REL) & - Accurate and Reliable Service (ARS) \\
\hline 2.Responsiveness (RESP) & $\begin{array}{l}\text { - Accurate Description of Product (ADP) } 1 \\
\text { - Sincere desire to Solve Problems for Customers (SSPC) } \\
\text { - Promptness in Response to Requests (PRR) } \\
\text { - Availability of Alternative Communication Channels (AACC) }\end{array}$ \\
\hline 3.Functional benefit & $\begin{array}{l}\text { - A fun working environment } \\
\text { - A springboard for future employment } \\
\text { - Gaining career-enhancing experience } \\
\text { - High-quality products and services }\end{array}$ \\
\hline 4.Efficiency & $\begin{array}{l}\text { - Mobility n } \\
\text { - Mean SD Pain n } \\
\text { - Mean SD Social n }\end{array}$ \\
\hline 5.Privacy & $\begin{array}{l}\text { - Social context } \\
\text { - System privacy } \\
\text { - Feeling of privacy }\end{array}$ \\
\hline 6.Satisfaction & $\begin{array}{l}\text { - Situational satisfaction. } \\
\text { - Reactional satisfaction } \\
\text { - Expectancy satisfaction }\end{array}$ \\
\hline
\end{tabular}

Table II. Alternatives and Factors for E-Commerce Service Quality

\begin{tabular}{|l|l|}
\hline Alternatives $(\mathrm{S})$ & \multicolumn{1}{|c|}{ Factors $(\mathrm{P})$} \\
\hline$\bullet$ FaceBook $\left(\mathrm{S}_{1}\right)$ & $\bullet$ Reliability $\left(\mathrm{P}_{1}\right)$ \\
\hline$\bullet$ IBM $\quad\left(\mathrm{S}_{2}\right)$ & $\bullet$ Funtional Benefit $\left(\mathrm{P}_{3}\right)$ \\
\hline$\bullet$ Microsoft $\left(\mathrm{S}_{3}\right)$ & $\bullet$ Efficiency $\left(\mathrm{P}_{4}\right)$ \\
\hline$\bullet$ Google $\left(\mathrm{S}_{4}\right)$ & $\bullet$ Privacy $\left(\mathrm{P}_{5}\right)$ \\
\hline$\bullet$ Coca-Cola $\left(\mathrm{S}_{5}\right)$ & $\bullet$ Satisfaction $\left(\mathrm{P}_{6}\right)$ \\
\hline$\bullet$ American Express $\left(\mathrm{S}_{6}\right)$ & \\
\hline
\end{tabular}

Table III. Intuitionistic Fuzzy Numbers for Linguistic Attributes

\begin{tabular}{|ll|l|}
\hline \multicolumn{2}{|l|}{ Linguistic variables } & IFNs \\
\hline Extremely high $\quad(\mathrm{EH})$ & $(1.0,0.0)$ \\
\hline Very high $\quad(\mathrm{VH})$ & $(0.9,0.05)$ \\
\hline High $\quad(\mathrm{H})$ & $(0.8,0.15)$ \\
\hline Medium High $\quad(\mathrm{MH})$ & $(0.7,0.2)$ \\
\hline Medium $\quad(\mathrm{M})$ & $(0.6,0.4)$ \\
\hline Medium low $\quad(\mathrm{ML})$ & $(0.45,0.5)$ \\
\hline Low $\quad(\mathrm{L})$ & $(0.35,0.6)$ \\
\hline Very low & $(0.2,0.7)$ \\
\hline Extremely low $\quad(\mathrm{EL})$ & $(0.1,0.9)$ \\
\hline
\end{tabular}

Table IV. Decision Makers Weight

\begin{tabular}{|l|l|l|l|}
\hline Decision experts & E1 & E2 & E3 \\
\hline Linguistic terms & VH & MH & H \\
\hline Ifns & & & \\
\hline Weights & $(0.9,0.05)$ & $(0.7,0.2)$ & $(0.8 .0 .15)$ \\
\hline
\end{tabular}


Table V. Linguistic Values Assigned by Decision Makers to the Top Brands

\begin{tabular}{|l|l|l|l|l|l|l|}
\hline & P1 & P2 & P3 & P4 & P5 & P5 \\
\hline S1 & E1: M & E1: M & E1: L & E1: ML & E1: L & E1: VL \\
& E2: ML & E2: L & E2: ML & E2: M & E2: VL & E2: L \\
& E3: M & E3: MH & E3: M & E3: L & E3: L & E3: VL \\
\hline S2 & E1: VH & E1: M & E1: M & E1: H & E1: H & E1: M \\
& E2: H & E2: H & E2: H & E2: H & E2: VH & E2: MH \\
& E3: M & E3: VH & E3: VH & E3: VH & E3: M & E3: M \\
\hline S3 & E1: VH & E1: VH & E1: H & E1: VH & E1: M & E1: H \\
& E2: H & E2: H & E2: VH & E2: H & E2: MH & E2: VH \\
& E3: M & E3: H & E3: H & E3: VH & E3: M & E3: H \\
\hline S4 & E1: VH & E1: H & E1: VH & E1: H & E1: MH & E1: H \\
& E2: VH & E2: H & E2: H & E2: VH & E2: H & E2: H \\
& E3: VH & E3: H & E3: VH & E3: H & E3: MH & E3: H \\
\hline S5 & E1: M & E1: M & E1: L & E1: L & E1: M & E1: M \\
& E2: L & E2: MH & E2: VL & E2: L & E2: L & E2: M \\
& E3: ML & E3: H & E3: L & E3: VL & E3: L & E3: M \\
\hline S6 & E1: L & E1: M & E1: MH & E1: L & E1: L & E1: M \\
& E2: M & E2: L & E2: L & E2: ML & E2: L & E2: ML \\
& E3: ML & E3: ML & E3: M & E3: L & E3: L & E3: M \\
\hline
\end{tabular}

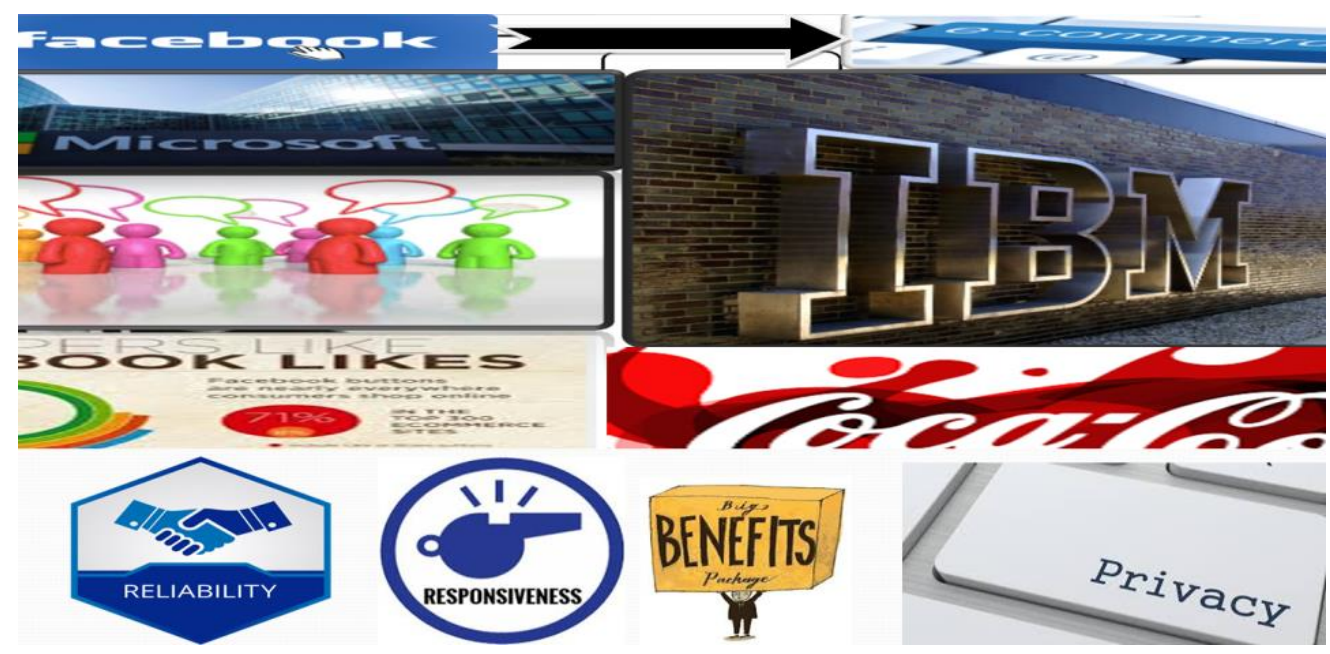

Fig.1. Top Brands and Classification Criteria

Table VI. Aggregated Matrix for Electronic Service Quality From (6)

\begin{tabular}{|l|l|l|l|l|l|l|}
\hline & P1 & P2 & P3 & P4 & P5 & P6 \\
\hline S1 & $(0.74,0.179)$ & $(0.59,0.34)$ & $(0.53,0.47)$ & $(0.45,0.49)$ & $(0.32, .62)$ & $(0.73,0.139)$ \\
\hline S2 & $(0.79,0.118)$ & $(0.83,0.11)$ & $(0.66,0.28)$ & $(0.84,0.10)$ & $(0.79,0.15)$ & $(0.64,0.31)$ \\
\hline S3 & $(0.87,0.07)$ & $(0.82,0.105)$ & $(0.85,0.14)$ & $(0.80,0.15)$ & $(0.64,0.34)$ & $(0.88,0.11)$ \\
\hline S4 & $(0.90,0.04)$ & $(0.79,0.11)$ & $(0.80,0.11)$ & $(0.84,0.14)$ & $(0.54,0.24)$ & $(0.80,0.14)$ \\
\hline S5 & $(0.48,0.51)$ & $(0.72,0.21)$ & $(0.32,0.62)$ & $(0.49,0.28)$ & $(0.45,0.52)$ & $(0.605,0.394)$ \\
\hline S6 & $(0.484,0.468)$ & $(0.423,0.524)$ & $(0.579,0.362)$ & $(0.48,0.28)$ & $(0.349,0.604)$ & $(0.498,0.431)$ \\
\hline
\end{tabular}

Table VII. Entropy Measure for Aggregated If Matrix From (9)

\begin{tabular}{|l|l|l|l|l|l|l|}
\hline & P1 & P2 & P3 & P4 & P5 & P6 \\
\hline S1 & 0.6362 & 0.9239 & 0.9956 & 0.9980 & 0.8910 & 0.5992 \\
\hline S2 & 0.4927 & 0.2805 & 0.8271 & 0.3971 & 0.5358 & 0.8686 \\
\hline S3 & 0.3090 & 0.4329 & 0.4399 & 0.5225 & 0.8910 & 0.3827 \\
\hline S4 & 0.2181 & 0.4818 & 0.4679 & 0.4540 & 0.8910 & 0.5090 \\
\hline S5 & 0.9981 & 0.6959 & 0.8910 & 0.9461 & 0.9940 & 0.9456 \\
\hline S6 & 0.9997 & 0.9874 & 0.9425 & 0.951 & 0.9208 & 0.9945 \\
\hline
\end{tabular}


Table VIII. Normalised Entrpy Matrix(10)

\begin{tabular}{|l|l|l|l|l|l|l|}
\hline & P1 & P2 & P3 & P4 & P5 & P6 \\
\hline S1 & 0.6363 & 0.9356 & 1.0000 & 1.0000 & 0.8963 & 0.6025 \\
\hline S2 & 0.4928 & 0.2840 & 0.8307 & 0.3978 & 0.5390 & 0.8734 \\
\hline S3 & 0.3091 & 0.4384 & 0.4418 & 0.5235 & 0.8963 & 0.3845 \\
\hline S4 & 0.2182 & 0.4879 & 0.4699 & 0.4549 & 0.8963 & 0.5118 \\
\hline S5 & 0.9984 & 0.7047 & 0.8949 & 0.9479 & 1.000 & 0.9508 \\
\hline S6 & 1.0000 & 1.0000 & 0.9466 & 0.952 & 0.9263 & 1.0000 \\
\hline $\bar{C}$ & 0.1414 & 0.1491 & 0.1773 & 0.1654 & 0.1994 & 0.1672 \\
\hline
\end{tabular}

$w=(0.1414,0.1491,0.1773,0.1654,0.1994,0.1672)^{T}$.

Table IX. Rank Calculations of Wsm and Wpm From (11).

\begin{tabular}{|l|l|l|l|l|l|l|}
\hline $\mathrm{S}$ & WSM & $\mathbb{S}^{*}\left(\phi_{k}\right)$ & Rank & WPM & $\mathbb{S}^{*}\left(\phi_{k}\right)$ & Rank \\
\hline$S_{1}$ & $(0.5735,0.3390)$ & 0.61725 & 4 & $(0.5242,0.4125)$ & 0.5558 & 4 \\
\hline$S_{2}$ & $(0.7682,0.1633)$ & 0.8034 & 3 & $(0.7518,0.1857)$ & 0.7083 & 2 \\
\hline$S_{3}$ & $(0.8183,0.1409)$ & 0.8387 & 1 & $(0.7984,0.1673)$ & 0.8155 & 1 \\
\hline$S_{4}$ & $(0.7922,0.1740)$ & 0.5169 & 2 & $(0.4638,0.1385)$ & 0.6626 & 3 \\
\hline$S_{5}$ & $(0.5564,0.4026)$ & 0.5769 & 5 & $(0.4886,0.4469)$ & 0.5208 & 5 \\
\hline$S_{6}$ & $(0.4718,0.4772)$ & 0.503 & 6 & $(0.4604,0.4583)$ & 0.501 & 6 \\
\hline
\end{tabular}

IF-TOPSIS method

Table X. Divergence Measures Of E-Sq with Positive-Ideal and Negative-Ideal Solution (12)\&(13)

\begin{tabular}{|l|l|l|l|l|l|l|}
\hline & P1 & P2 & P3 & P4 & P5 & P6 \\
\hline S1 & $(0.74,0.179)$ & $(0.59,0.34)$ & $(0.53,0.47)$ & $(0.45,0.49)$ & $(0.32, .62)$ & $(0.73,0.139)$ \\
\hline S2 & $(0.79,0.118)$ & $(0.83,0.11)$ & $(0.66,0.28)$ & $(0.84,0.10)$ & $(0.84,0.14)$ & $(0.64,0.31)$ \\
\hline S3 & $(0.87,0.07)$ & $(0.82,0.105)$ & $(0.85,0.14)$ & $(0.80,0.15)$ & $(0.64,0.34)$ & $(0.88,0.14)$ \\
\hline S4 & $(0.90,0.04)$ & $(0.79,0.11)$ & $(0.80,0.11)$ & $(0.84,0.14)$ & $(0.54,0.24)$ & $(0.80,0.14)$ \\
\hline S5 & $(0.48,0.51)$ & $(0.72,0.21)$ & $(0.32,0.62)$ & $(0.49,0.28)$ & $(0.45,0.52)$ & $(0.605,0.394)$ \\
\hline S6 & $(0.484,0.468)$ & $(0.423,0.524)$ & $(0.579,0.362)$ & $(0.48,0.28)$ & $(0.349,0.604)$ & $(0.498,0.431)$ \\
\hline$\left(E^{+}\right)$ & $(0.90,0.04)$ & $(0.83,0.11)$ & $(0.85,0.14)$ & $(0.84,0.14)$ & $(0.84,0.14)$ & $(0.88,0.14)$ \\
\hline$\left(E^{-}\right)$ & $(0.48,0.51)$ & $0.423,0.524)$ & $(0.32,0.62)$ & $(0.45,0.49)$ & $0.32, .62)$ & $(0.498,0.431)$ \\
& & & & & & \\
\hline
\end{tabular}

Table XI. Relative Closeness of E-Sq (14)

\begin{tabular}{|c|l|l|l|l|}
\hline Attributes & $h\left(E_{i}, E^{+}\right)$ & $h\left(E_{i}, E^{-}\right)$ & $\mathbb{S}\left(E_{i}\right)$ & Rank \\
\hline E1 & $h\left(E_{1}, E^{+}\right)=0.0842$ & $h\left(E_{1}, E^{-}\right)=0.287$ & $\mathbb{S}\left(E_{1}\right)=0.2542$ & 5 \\
\hline E2 & $h\left(E_{2}, E^{+}\right)=0.0166$ & $h\left(E_{2}, E^{-}\right)=0.1167$ & $\mathbb{S}\left(E_{2}\right)=0.8754$ & 2 \\
\hline E3 & $h\left(E_{3}, E^{+}\right)=0.00636$ & $h\left(E_{3}, E^{-}\right)=0.1278$ & $\mathbb{S}\left(E_{3}\right)=0.9525$ & 1 \\
\hline E4 & $h\left(E_{4}, E^{+}\right)=0.1019$ & $h\left(E_{4}, E^{-}\right)=0.1068$ & $\mathbb{S}\left(E_{4}\right)=0.5117$ & 4 \\
\hline E5 & $h\left(E_{5}, E^{+}\right)=0.1298$ & $h\left(E_{5}, E^{-}\right)=0.141$ & $\mathbb{S}\left(E_{5}\right)=0.5206$ & 3 \\
\hline E6 & $J\left(E_{6}, E^{+}\right)=0.1231$ & $J\left(E_{6}, E^{-}\right)=0.0109$ & $\mathbb{S}\left(E_{6}\right)=0.0813$ & 6 \\
\hline
\end{tabular}




\section{CONCLUSIONS}

This advancement is an assimilation of Weighted Product Model (WPM) and Weighted Sum Model (WSM). TOPSIS (Technique for Order Preference by Similarity to Ideal System) algorithm to rank the rising development of services and the increasing compliance of information and communication technology as a transposing medium, through Internet using facebook acoounts of top ranking social commerce companies, the criterion weight is evaluated by proposed divergence measure for IFSs. This will help in outranking the top performer with providing highest rank rank. Therefore, it may help consumers to consider only the ranked service providers in MP work. In this paper the service quality of e-commerce websites is calculated through comparing Weighted Product Model (WPM) and Weighted Sum Model (WSM). TOPSIS (Technique for Order Preference by Similarity to Ideal System) methods so that it may help the consumers to chose the best service providers and also to the top brand companies improve the services by benchmarking the top ranker.

\section{REFERENCES}

[1] A. Saxena, U. Khanna, "Advertising on social network sites: A structural equation modelling approach. Vision," The Journal of Business Perspective, 17(1),17-25, 2013.

[2] A.R. Mishra, "Intuitionistic fuzzy information measures with application in rating of township development," Iran J Fuzzy Syst, vol. 13(3), pp. 49-70, 2016.

[3] A.R. Mishra, P. Rani Biparametric information measures based TODIM technique for interval valued intuitionistic fuzzy environment. Arabian Journal for Science and Engineering 43(6):3291- 3309,2018 .

[4] A.R. Mishra, P. Rani Shapley, "Divergence measures with VIKOR method for multi attribute decision making problems," neural network and computing, 2017, DOI:10.1007/s00521-017-3101-x.

[5] A.R. Mishra, P. Rani, D. Jain, "Information Measures Based TOPSIS Method for Multi-criteria Decision Making Problem in Intuitionistic Fuzzy Environment," Iranian Journal of Fuzzy Systems, vol. 14(6), pp. 41-63, 2017.

[6] Al Dmour, H., Alshurideh, M., Shishan, F. "The influence of mobile application quality and attributes on the continuous intention of mobile application," Life Science Journal , vol.11(10):172-181,2014.

[7] Ansari MD, Mishra AR, Ansari FT (2018) New divergence and entropy measures for intuitionistic fuzzy sets on edge detection. International Journal of Fuzzy Systems 20(2):474-487.

[8] AR Mishra, P Rani, KR Pardasani "Multiple-criteria decision-making for service quality selection based on Shapley COPRAS method under hesitant fuzzy sets," Granular Computing, https://doi.org/10.1007/s41066-018-0103-8

[9] AR Mishra, RK Singh, D Motwani, "Multi-criteria assessment of cellular mobile telephone service providers using intuitionistic fuzzy WASPAS method with similarity measures," Granular Computing, $2018 \mathrm{~b}$.

[10] C.Liu, K. P. Arnett, "Exploring the factors associated with Web site successin the context of electronic commerce," Information \& Management, vol. 38(1), pp. 23-33, 2000

[11] D. M. Szymanski, R. T. Hise, "E-satisfaction: An initial examination.," Journal of Retailing, vol. 76(3), pp. 309322, 2000.

[12] D.C. Edelman, "Branding in the digital age: You're spending your money in Aall the wrong places," Harvard Business Review, vol. 88(12), pp. 64-69, 2010.

[13] D.Court, D.Elingza, S.Mulder, O. Vevtik, “ The consumer decision journey," mckensy quaterly, pp.1-11, 2009.

[14] $\mathrm{De}^{\cdot}$ jus titas, antuchevic `iene jurgita, journal of civil engineering and management vol, 19(5), pp. 728737, 2013.

[15] E. -J. Lee, S.Y. Shin, "When do consumers buy online product reviews? Effects of review quality," product type, and reviewer's photo.Computers in Human Behavior,vol. 31, pp.356-366, 2014.

[16] E.Constantinides, L.R Romeo, M.A.G Boria "Social media: A new frontier for retailers?," European Retail Research, vol. 22, pp.1-28, 2008.

[17] E.Triantaphyllou, and S.H. Mann, "An examination of the effectiveness of multi-dimensional decision-making methods: A decision-making paradox," International Journal of Decision Support Systems, 5, 303-312, 1989.

[18] E.K.Zavadskas, Z.Turskis, J. Antucheviciene, Zakarevicius, " Extention if weighted aggregated sumproduct assessment with IVIF,vol. 24, pp. 1013 $21,2014$.

[19] E. K Zavadskas, Z.Turskis, J. Antucheviciene, A. Zakarevicius, "Optimization of Weighted Aggregated Sum Product Assessment. Electronics and Electrical engineering," vol. 6(122), pp. 3-6, 2012.

[20] Eulalia Szmidt, Janusz Kacprzyk, "Entropy for intruitionistic fuzzy sets," Fuzzy sets systems, vol. 118, pp.467-477, 2001.

[21] H.Hu, J.kandampully, T.D. Juwaheer, "Relationships and impacts of service quality perceived value customer satisfaction and image: an empirical study," The Service Industries Journal, vol. 29, pp.111-125, (2009).

[22] I. Montes, N.R. Pal, V Janis, S. Montes, "Divergence measures for intuitionistic fuzzy sets," IEEE Trans Fuzzy Syst, vol. 23, pp. 444-456, 2015.

[23] J. Q. Zhang, G. Craciun, D. Shin, "When does electroonic word-of-mouth matters: A study of cstomer prodution reviews," Journal of Business Research, vol. 63(12), pp. 1336-1341, (2010).

[24] J. Saparauskas, E. K. Zavadskas, Z. Turskis, "Selection of facade's alternatives of commercial and public buildings based on multiple criteria," International Journal of Strategic Property Management, vol.15. 189-203, 2011.

[25] J.J Cronin, M.K. Brady, and G.T. Hult, "Assessing the Effects of Quality Value and Customer Satisfaction on Consumer Behavioral Intentions in Service Environments," Journal of Retailing, vol. 76, pp.193-218.

[26] K.Atanassov, "Intuitionistic fuzzy sets," Fuzzy Sets Syst, vol.20, pp.87-96, 1986.

[27] L. B. Abhang, M. Hameedullah, "Optimizing of machining parameters in steel turning operations," Procedia Engineering, vol.38, pp. 40- 48, 2012.

[28] Mahdi Bitarafan, Sarfaraz Hashemkhani Zolfani, Shahin Lale Arefi, Edmundas Kazimier Zavadskas, AmirMahmoudzadeh, "Develeoping a new hybrid MCDM method for selection optimal alternative for mrchanical longitudenal ventilation of tunnel pollution during mobile accidents,"Te Baltic Journal of Road and Bridge Engineering, vol. 9(4), pp. 333-340, 2013. 
[29] N. Michaelidou, N.T. Siamagka,G. Christodoulides, "usage barriers and measurement of social media marketing: an exploratory investigation for small and medium B2B brands," Industrial Marketing Management, vol. 40(7), pp. 1153-1159, 2011.

[30] Nikunj Patel, "Insert selection forturning operation on CNC turning centre using MADM methods," International Journal of Latest Trends in Engineering and Technology, vol.1(3), pp. 49-59, 2012.

[31] P. Greenberg, 'Do We Really NEED CRM 2.0?', $\mathrm{http} / / / \mathrm{blogs} . z d n e t . c o m / \mathrm{crm} /$ ?cat=5 accessed 27/04/09(2009)

[32] P Rani, D Jain, "Intuitionistic fuzzy PROMETHEE technique for multi- criteria decision making problems based on entropy measure.," In Proceedings of Communications in Computer and Information Science (CCIS), Springer 721:290-301, 2017

[33] P Rani, D Jain, DS Hooda , " Shapley function based interval-valued intuitionistic fuzzy VIKOR technique for correlative multi-criteria decision making problems," Iranian Journal of Fuzzy Systems, vol.15(1), pp.25-54, 2018b.

[34] P. Alpar, M. Porembski, \& S. Pickerodt, "Measuring the efficiency of website traffic management," International Journal of Electronic Commerce, vol.6(1), pp. 53-74, 2001.

[35] R. W. Naylor, C. P. Lamberton, P. M. West, "The impact of mere virtual presence on brand evaluations and purchase intentions in social media settings." Journal of Marketing, vol.76(6), pp. 105-120, 2012.

[36] R.Rust, "The rise of e-service," journel of service research, vol. 3(4), pp. 283-5,2001.

[37] Rani P, Jain D, Hooda DS (2018a) Extension of intuitionistic fuzzy TODIM technique for multicriteria decision making method based on Shapley weighted divergence measure. Granular Computing https://doi.org/10.1007/s41066-018-0101-x

[38] S. Mohan, E. Choi, Dugki Min, "Domain specific modeling of bussiness processes and entity mapping using generic moddeling environment," International conference on converge and hybrid Information technology, vo.1, pp. 136-702, 2008.

[39] S.Chakraborty, E.K.Zavadskas, "Applications of WASPAS method in manufacturing decision making," Informatica:An international journel computing and informatics, vol. 25, pp. 1-20, 2014

[40] S.Hashemkhani Zolfani, M.Farrokhzad, M. H. Aghdaie, A.derakhti, E.K. Zavadskas, M.H Morshed Varzandeh, "Decision making on bussiness issues with foresight perspective; an application of new hybrid MCDM model in shopping mall locating," Economics and Management, vol. 16(2), pp. 290-306, 2013c.

[41] T. P. Dong, N.P. cheng, Wu Y.C.J, "A study on social networking website in digital content industries the facebook case in Taiwan,Computers in human behavior, vo. 30,708-714, 2014.

[42] T.Kuo, H.L. Tang, "Relationships among activities - A case of Taiwanese college students," Computers in Human Behavior, vol. 31, pp. 13-19, 2014.

[43] V. A. Zeithaml, A. Parasuraman, A. Malhotra, "Service quality delivery through websites : a critical review in extant knowledge," Journal of the Academy of Marketing Science, vol. 30(4), pp. 362-375, 2002.
[44] V. M. Athawale.A comparative study on the ranking performance of some multi criteria decision making of industrial robot managment, International Conference on Industrial Engineering and Operations Management, vol .2(4), pp.831-850, 2010.

[45] Wu, Y.C. J., et al, "Electronic service quality of Facebook social commerce and collaborative learning," Computers in Human Behavior (2015), http://dx.doi.org/10.1016/j.chb.2014.10.001

[46] Y. Zhilin , F. Xiang, "Measuring customer percieved online service quality : scale development and mangerial implications," International journel of service industry management, vol. 15, pp. 302-326, 2004.

[47] Y.C. J. Wu, et al, "Electronic service quality of facecook social commerce and collaborative learning," Computers in Human Behavior, pp. 1-8, 2015, doi.org/10.1016/j.chb.2014.10.001.

[48] Y.Ku, R.Cheng, H.Zhang, "Why do userscontinue using social networking sites?an exploratory Study of members in the united States and Taiwn," Information and management, vol.50(7), pp.571-81,2013.

\section{Authors' Profiles}

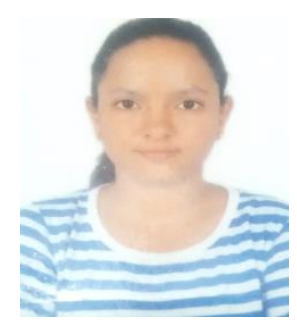

Gaurisha sisodia is pursuing M.tech from ITM University Gwalior, M.P., India in computer science. she is received his B.Tech.in computer science from ITM university,gwalior, India

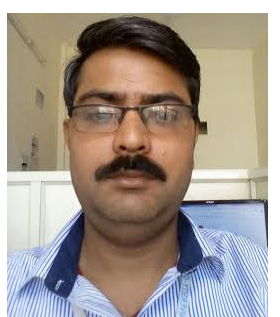

Kapil Sharma is pursuing Ph.D. from ITM University Gwalior, M.P., India in Trust Management in Vehicular Ad hoc Networks. He is received his M.Tech. and B. Tech. in Information Technology from R.G.P.V., Bhopal, India. He is an Assistant Professor at ITM University Gwalior, India.

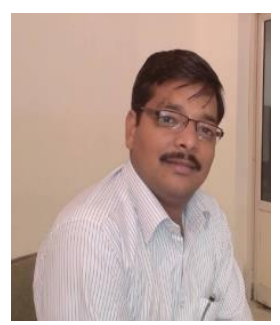

Dr. Shashi Kant Gupta working as Associate Professor in ITM University Gwalior. He has completed his PhD from Nims University Jaipur in wireless sensor network 
How to cite this paper: Gaurisha Sisodia, Kapil Sharma, Shashikant Gupta, " Intuitionistic Fuzzy Weighted Sum and Product Method for Electronic Service Quality Selection Problem", International Journal of Modern Education and Computer Science(IJMECS), Vol.10, No.9, pp. 33-43, 2018.DOI: 10.5815/ijmecs.2018.09.05 